\title{
Gold Nanowires from Nanorods
}

Bishnu P. Khanal and Eugene R. Zubarev*

Department of Chemistry, Rice University, 6100 Main Street, Houston, TX 77005, United States

*Corresponding author: zubarev@rice.edu

Supporting Information (SI) 


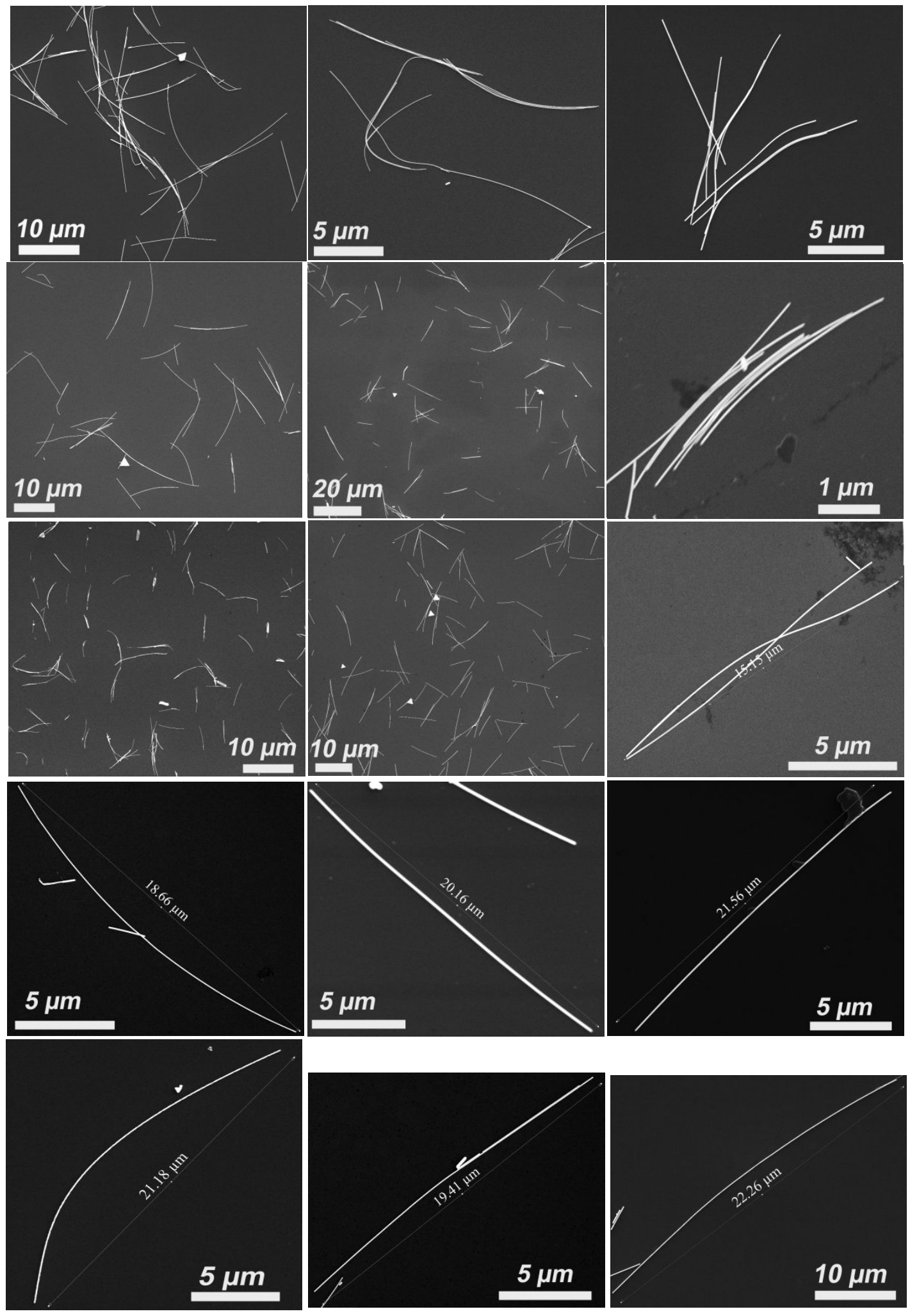

Figure SI 1. SEM images AuNWs of various sizes at higher magnification. The AuNWs are completely isolated and no bundle formation or crossed linking were observed. However, nanowires tend to come close which is due to quick precipitation and evaporation of solvent during sample preparation. 

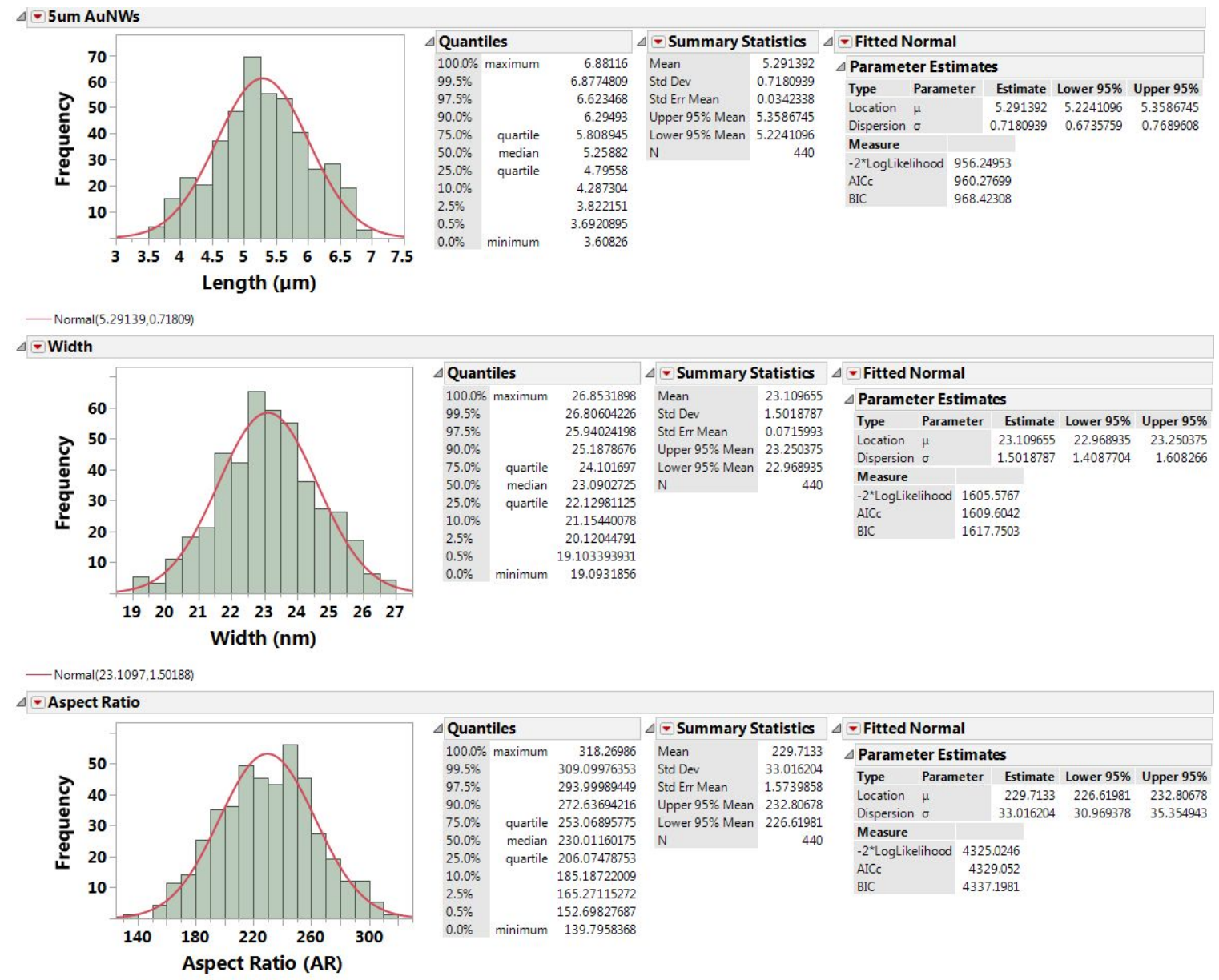

Figure SI 2. Statistical data analysis for the dimensions and aspect ratio of AuNWs synthesized by using $12.50 \mu \mathrm{mol}$ of $\mathrm{Au}(\mathrm{I})$ in growth solutions. Representative SEM images shown in main text Fig 1 and SI 1 were used for the size calculations. 

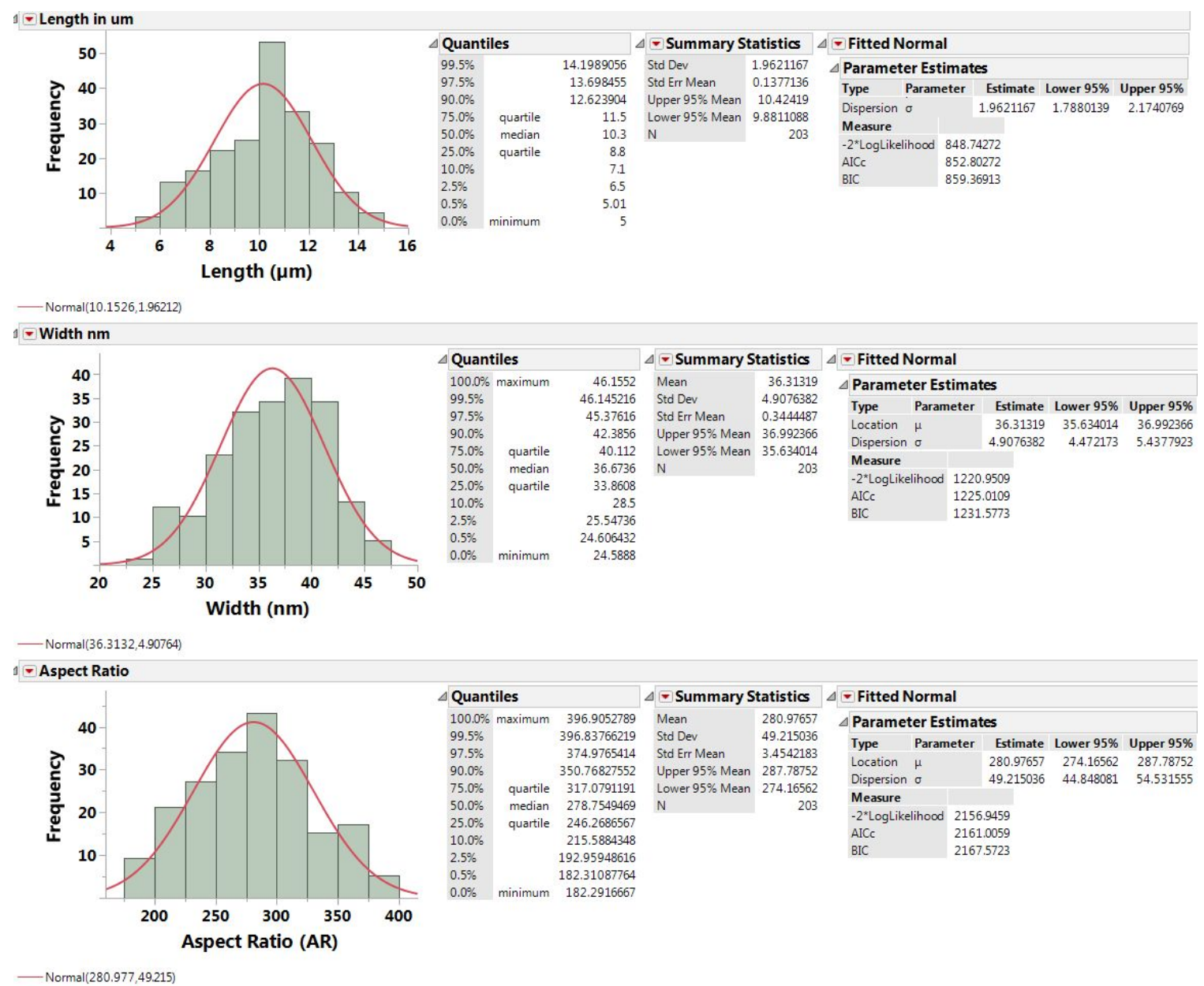

Figure SI 3. Statistical data analysis for the dimensions and aspect ratio of AuNWs synthesized by using $25.01 \mu \mathrm{mol}$ of $\mathrm{Au}(\mathrm{I})$ in growth solutions. Representative SEM images shown in main text Fig 1 and SI 1 were used for the size calculations. 

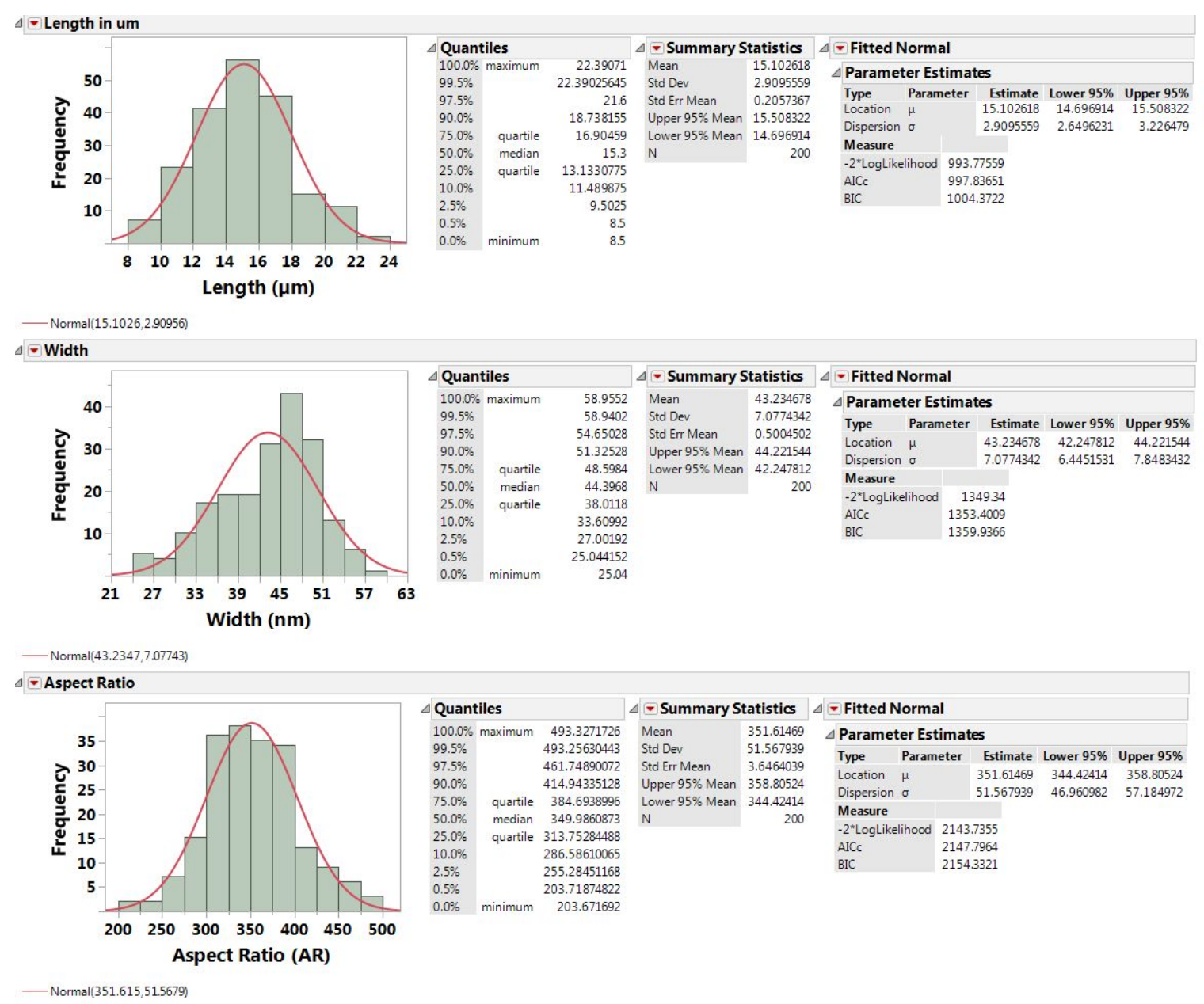

Figure SI 4. Statistical data analysis for the dimensions and aspect ratio of AuNWs synthesized by using $50.02 \mu \mathrm{mol}$ of $\mathrm{Au}(\mathrm{I})$ in growth solutions. Representative SEM images shown in main text Fig 1 and SI 1 were used for the size calculations. 

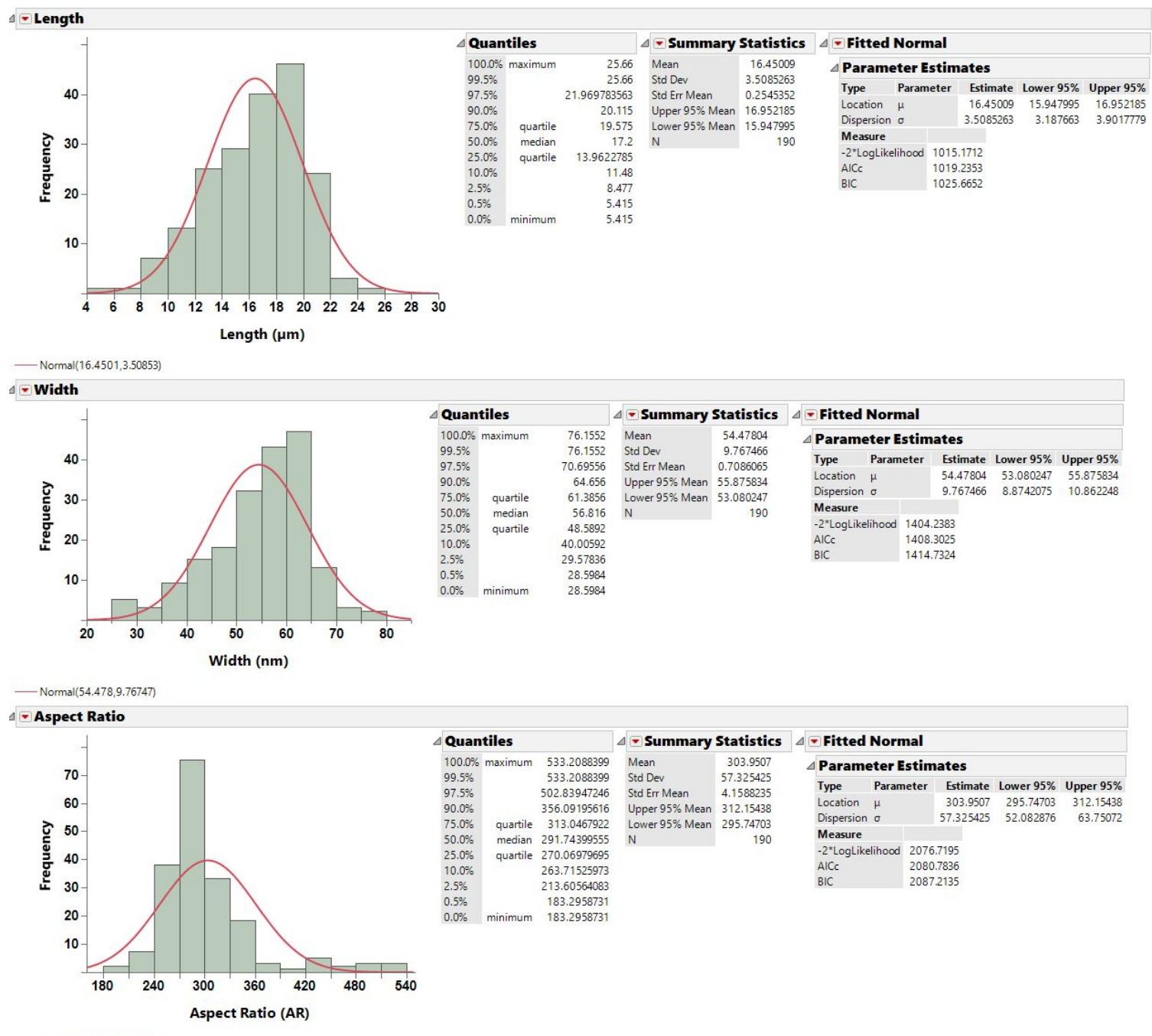

Figure SI 5. Statistical data analysis for the dimensions and aspect ratio of AuNWs synthesized by using $75.03 \mu \mathrm{mol}$ of $\mathrm{Au}(\mathrm{I})$ in growth solutions. Representative SEM images shown in main text Fig 1 and SI 1 were used for the size calculations. 

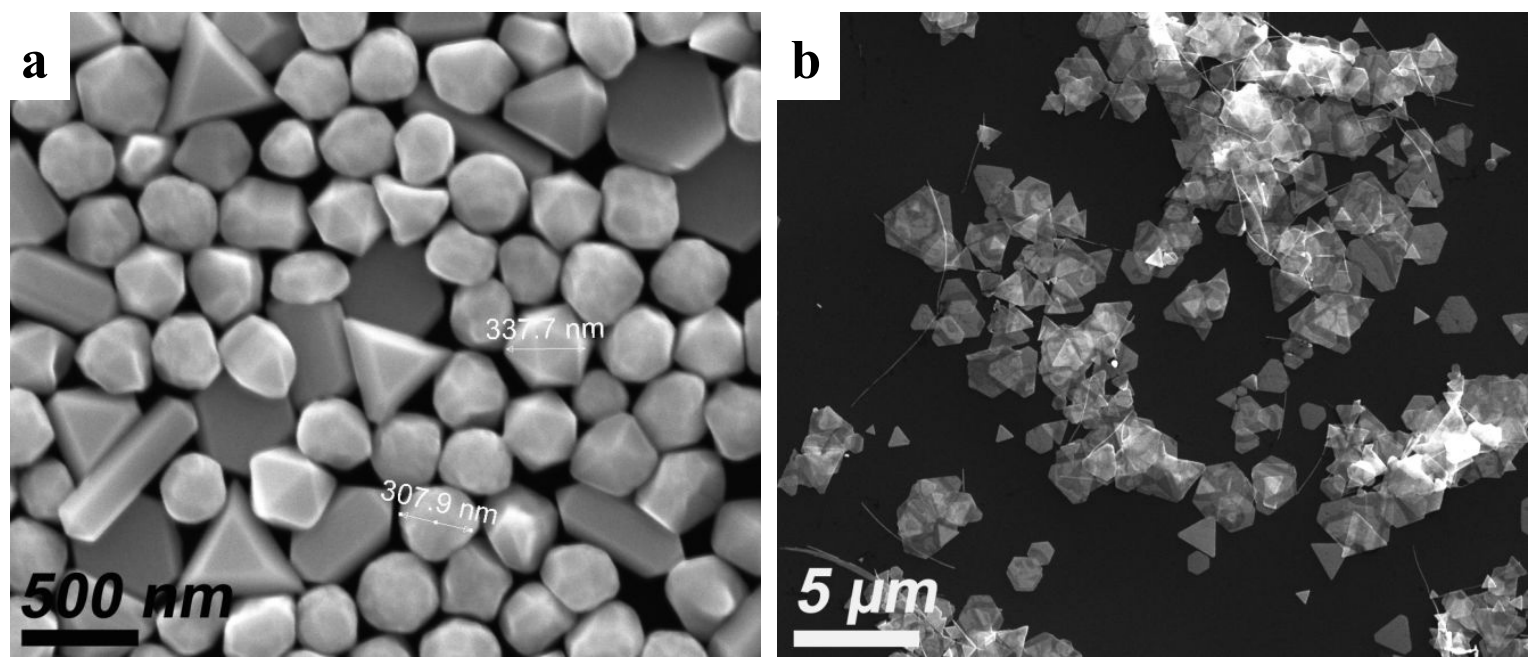

Figure SI 6. SEM image of overgrown (a) spherical particles and (b) 2D platelets
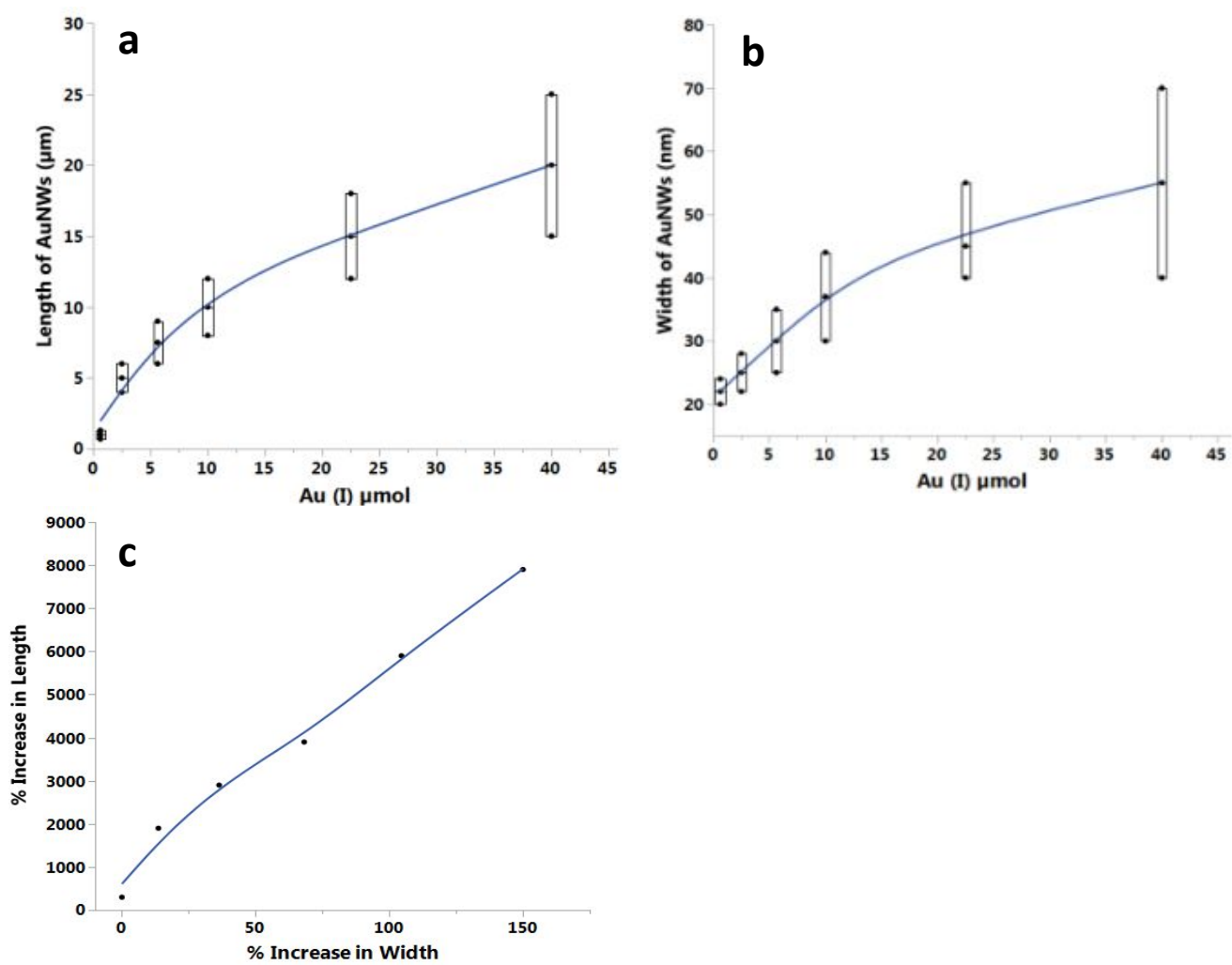

Figure SI 7. Graphs showing the increase in length (a) and width (b) of AuNWs with the amount of $\mathrm{Au}(\mathrm{I})$ ions in the growth solution. The errors bar are the range of AuNWs size ( $>80 \%$ of populations). Panel (c) shows the \% increase in length and width of AuNWs starting from AuNRs ( 250 nm x $22 \mathrm{~nm})$ 


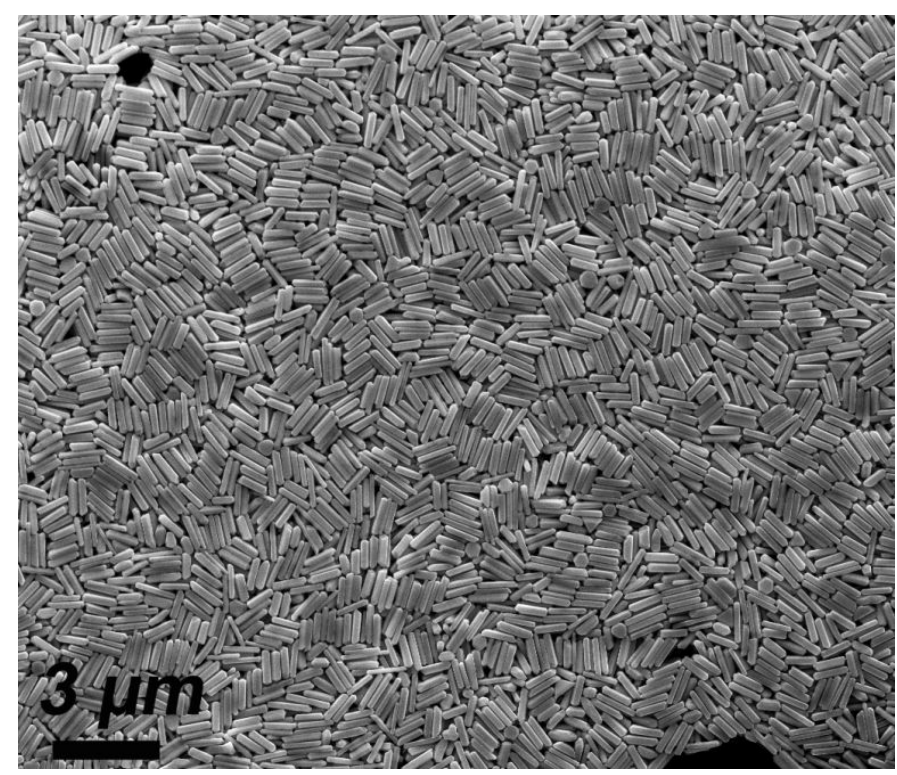

Figure SI 8. SEM images of gold microrods formed by the uniform deposition of Au atoms around pre-formed AuNRs.

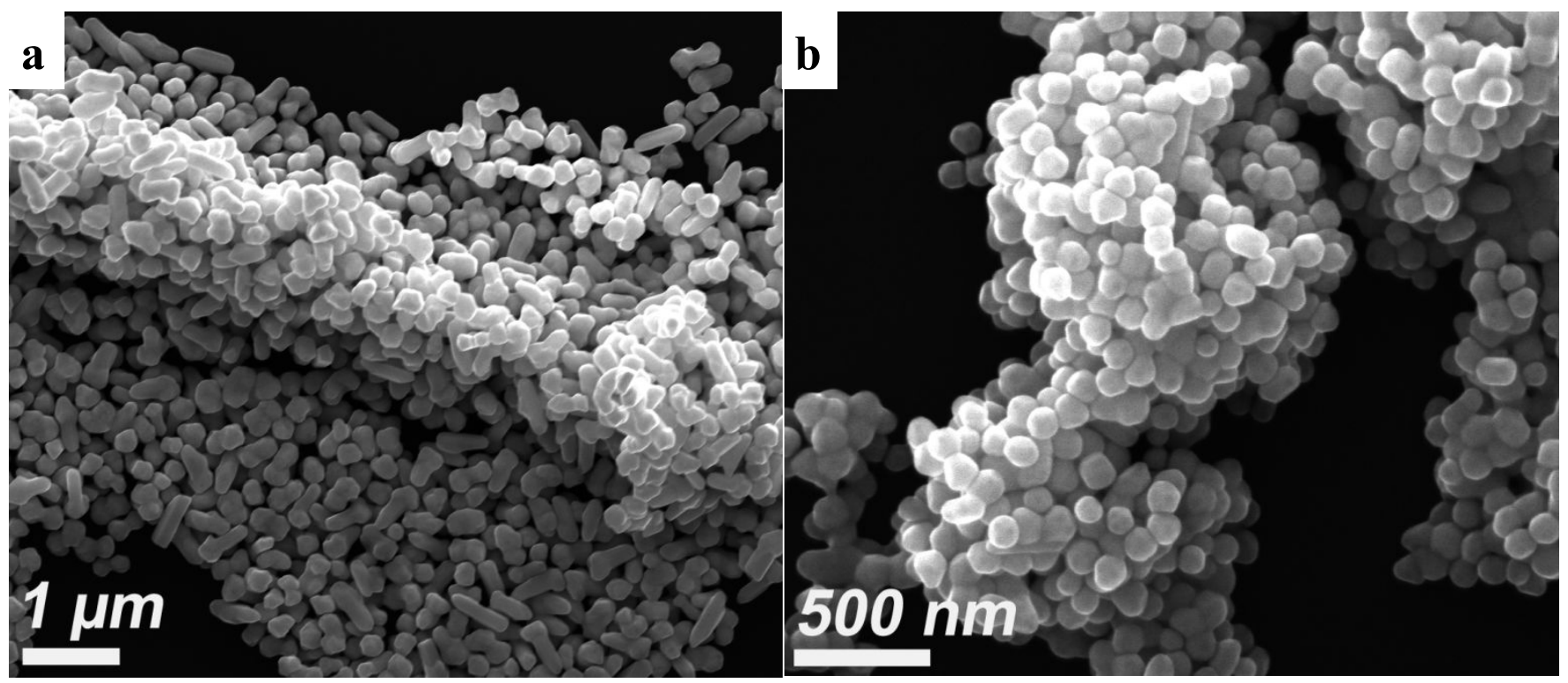

Figure SI 9. SEM images of single crystalline AuNRs grown at low pH (a) at low concentration of $\mathrm{Au}(\mathrm{I})$ and (b) at high concentration of $\mathrm{Au}(\mathrm{I})$ ions in growth solution. 


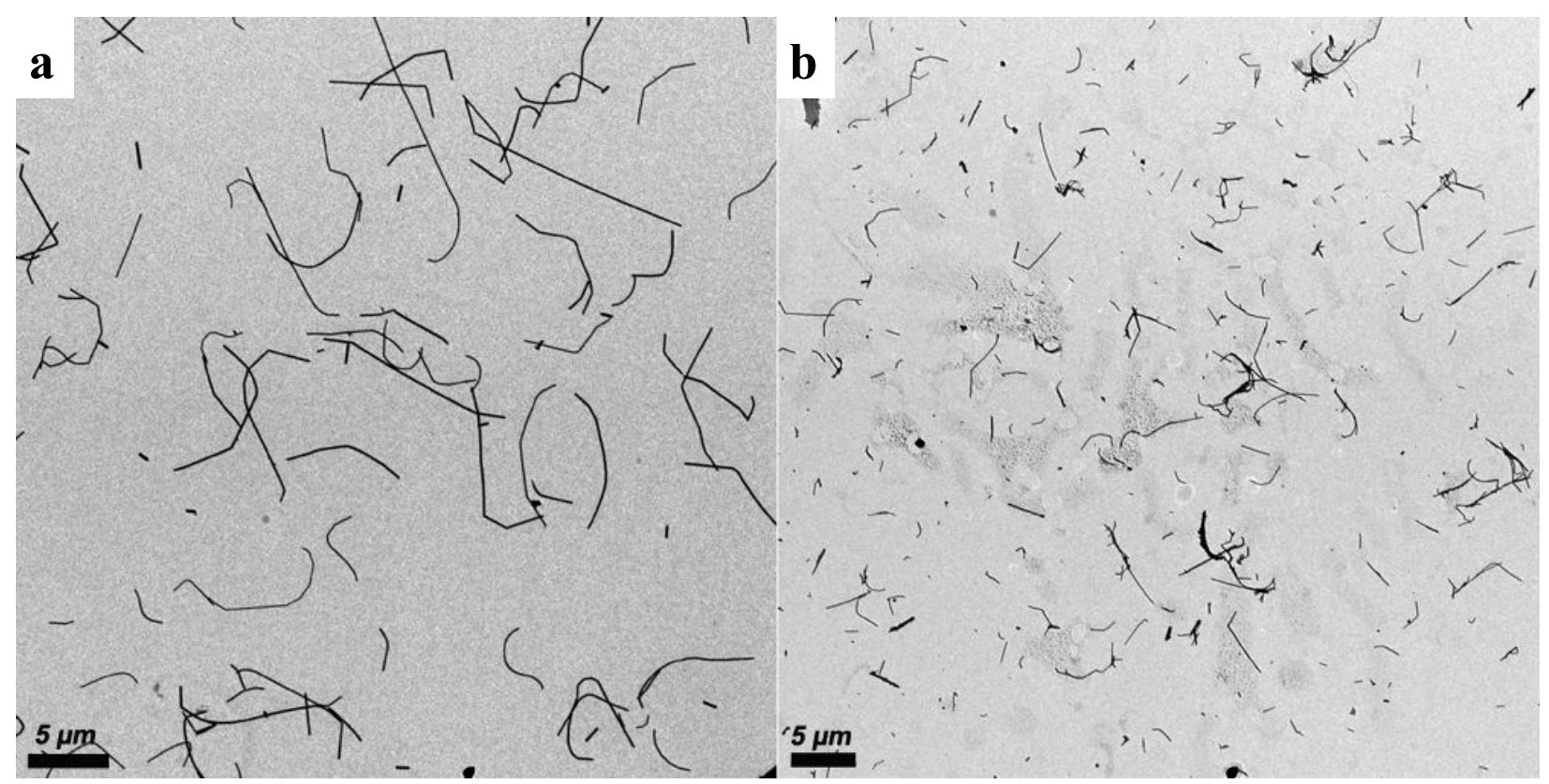

Figure SI 10. TEM images AuNWs after $60 \mathrm{sec}$ (a) and $300 \mathrm{sec}$ (b) of microwave radiation exposure. There were kinks formation at the surface of AuNWs at $60 \mathrm{sec}$ exposure; however after $300 \mathrm{sec}$ of exposure, all the nanowires broke into smaller fragments.

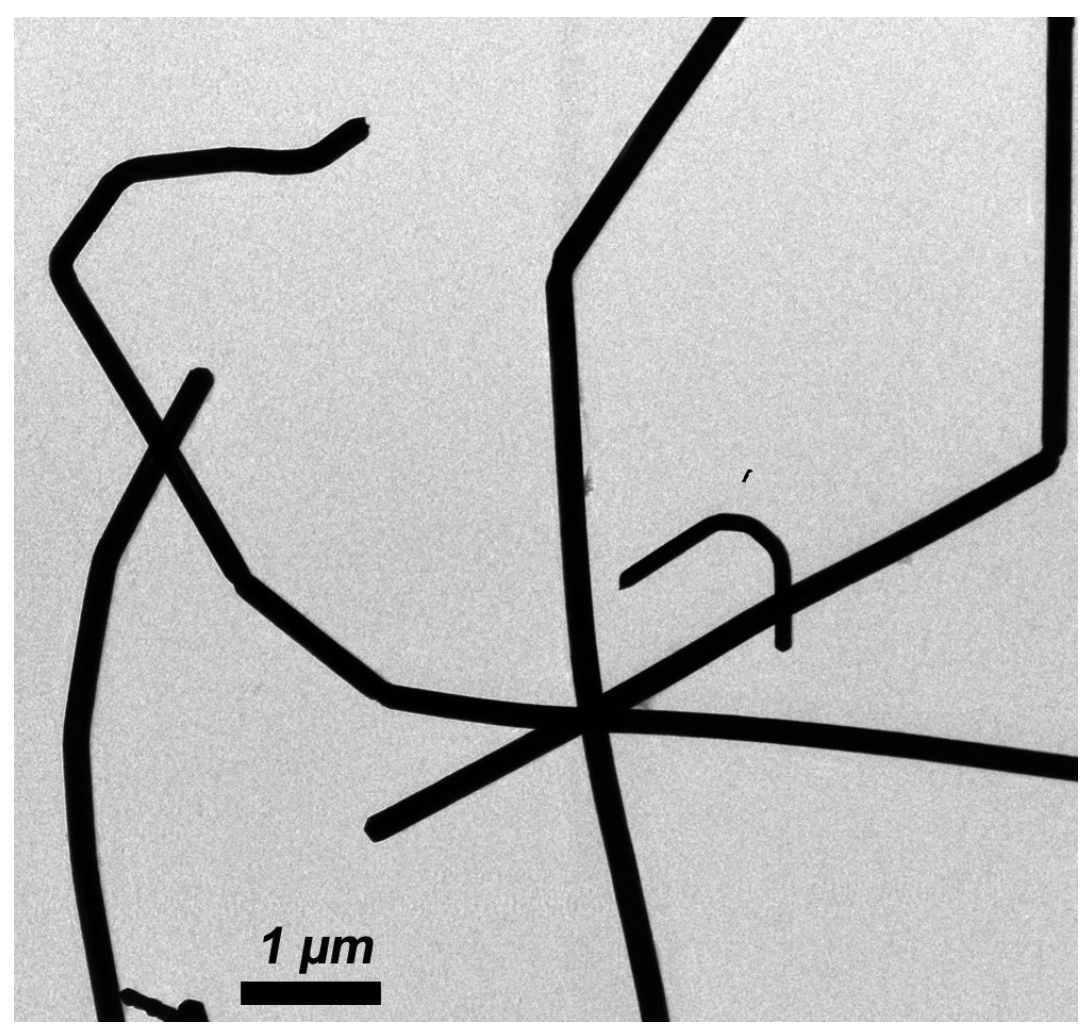

Figure SI 11. TEM images thicker AuNWs after $60 \mathrm{sec}$ of microwave radiation exposure. Irrespective of thickness kink formation on AuNWs was observed during microwave radiation exposure. 